\title{
Collaboration through Communities of Practice in the Digital Age
}

By: Fatih Oguz, Corrie V. Marsh, and Cliff Landis

Oguz, F, Marsh, C., \& Landis, C. (2010). Collaboration through communities of practice in the digital age. Communications in Computer and Information Science (Proceedings of the 2nd International Symposium on Information Management in a Changing World), 96, 1830. Heidelberg, Germany: Springer.

\section{***Note: This version of the document is not the copy of record. Made available courtesy of Springer Verlag: http://www.springerlink.com/,}

\begin{abstract}
:
This paper aims to describe and explain the role of Communities of Practice (CoPs) as an informal communication mechanism in initiating, improving, and fostering collaboration in the digital age. CoPs play a critical role in the management of shared knowledge and create value for both their members and organizations. The advent of the Internet and specifically the World Wide Web (WWW) has forever changed the means of accessing and sharing data and information. With the inception of Web 2.0 technologies and social-networking sites in recent years, connections and relationships are now not only nurtured and sustained in an online environment, but also established through creating virtual communities. The authors also assert that the inception of Web 2.0 technologies and social-networking sites is a great advancement in providing a rich learning, communication, and collaborative environment, especially through the transfer of tacit knowledge that we take for granted in our face-to-face interactions. These reflections are based on personal communications with members of virtual CoPs and literature on the impact of CoPs on decision-making and knowledge management.
\end{abstract}

\section{Article:}

\section{INTRODUCTION}

The phenomenon of Communities of Practice (CoPs) has been around for years, and the term itself was first used by Lave and Wenger (1991) while studying apprenticeship as a learning model. They argued that the acquisition of knowledge is a social process (Hildreth \& Kimble, 2004). CoPs are composed of people who share a concern, common problems, or a passion about a domain, and who want to gain more knowledge and expertise pertaining to that domain through regular interaction (Wenger et al., 2002).

CoPs provide a learning environment through social participation, where participation encompasses much more than engaging in joint activities. Here, it refers to participants being active in the practice and building an identity associated with the CoP to which they belong. Members become aware of their peers' expertise, knowledge, and skills as they engage and interact with each other. They are then able to compare, verify, and benchmark their professional expertise aligned with their colleagues' knowledge.

In addition, CoPs have the ability to deal with a broad range of knowledge-related issues by connecting isolated professionals with expertise, and linking unconnected activities pertinent to the domain. The individuals that participate in CoPs, as well as the organizations that support and provide resources to them, see value in CoPs for themselves. In the short run, CoPs improve the business outcomes for organizations by providing an arena for problem solving, quick answers to questions, different perspectives on issues, collaboration, and improved quality of decisions. For the members, CoPs may improve their work performance by providing them with access to expertise and knowledge through new ideas and solutions to challenges. However, in the long- 
run, CoPs develop organizational capabilities by letting organizations envision technological developments and take advantage of emerging market opportunities. For the members, CoPs also foster professional development by helping members to expand their knowledge and expertise in addition to improving their professional reputation (Wenger et al., 2002).

The latest innovations in social media and Web 2.0, are proving to be valuable tools in promoting knowledge creation, dissemination, and preservation. Social-networking sites including LinkedIn, Second Life, YouTube, and Facebook, as well as and other interactive Web 2.0 technologies and standards such as Wikis, Blogs, AJAX , and RSS feeds improve the richness of the information landscape in terms of communicability and interactivity that is traditionally inherent in face-toface interpersonal interactions. For example, Wikipedia has brought together a community of contributors from around the world through a user-driven Web 2.0 wiki application which was originally developed to facilitate communication among computer programmers in the 1990s. Bejune (2007) has identified a number of wikis in the library community to initiate, facilitate, and support collaboration among librarians and their users about various subject areas. Gannon-Leary and Fontainha (2007) have noted that virtual CoPs are widely adopted among academics and students as information communication technologies, utilizing e-mail discussion lists and discussion boards since these forms of communication mechanisms have become more userfriendly and interactive.

As commercial organizations expand in size, geographical coverage, and complexity, knowledge has become the key to improving organizational performance. Therefore, the formation of informal social structures like CoPs have become a natural part of organizational life (Lesser \& Storck, 2001; Wenger et al., 2002). CoPs make knowledge an integral part of their ongoing activities and interactions. Inter-personal interactions play an important role, especially in sharing tacit knowledge and the learning tools utilized by CoPs such as storytelling, conversation, and apprenticeship, increase the efficient use of knowledge. CoPs act as a "living repository" for collective knowledge by creating a value for both the members and the organizations supporting and sponsoring these social structures (Wenger et al., 2002).

\section{CHARACTERISTICS OF COMMUNITIES OF PRACTICE}

According to Wenger, a CoP is composed of three crucial characteristics: domain, community, and practice, which together provide a guide to community development and distinguish a CoP from other social structures, such as a project team or neighborhood community.

A domain defines a community through a common framework and identity. It addresses the issues related with a community's purpose such as topics, issues, and benefits pertinent to its members so that a common understanding of the domain can be developed within the community. The domain determines boundaries and guides its members about what is worth sharing and pursuing. It provides them with a direction through which members and other stakeholders are connected to the community. A shared domain encourages members to contribute and participate, and, therefore, provides a sense of accountability to the knowledge that is a distilled product of collective learning.

Wenger et al. (2002) define a community as a group of people who engage in joint learning activities, build relationships, and help each other regularly in pursuing their interests in the domain. Continuity in their interactions lets them develop a sense of belonging, identity, and commitment (Wenger et al., 2002). Nonaka (1994) argues that individual commitment is critical to knowledge creation within an organization, since it keeps members engaged in the community affairs. Interpersonal relationships are critical in community building. Knowing "who knows what" (Cross et al., 2001) makes it easier and efficient for the members to get the 'right answers' they need. In addition, inter-personal relationships enable members to overcome the initial trust 
issues that may arise when members engage in information sharing activities. Moreover, interpersonal interaction is an effective way of building trust, which is a precondition for genuine knowledge sharing and collaboration (Persaud et al., 2001).

A practice is defined as the set of frameworks, tools, ideas, knowledge, and documents a community develops, shares, and maintains (Wenger et al., 2002). It refers to the work a CoP's members do and their shared understandings and activities (Borgatti, 2004). Moreover, a practice gradually changes as a collective product of a community. The practice is oriented both to past and future. On the one hand, it explores existing knowledge that has been built up and shaped over time by the participants and embodies the history of the community. On the other hand, it looks into the latest advances in the field and thus enables members to handle new situations.

Although a CoP provides its members with a common domain, it does not imply that members have similar backgrounds, skills, and perspectives. A kind of homogeneity may accelerate the community building efforts at the early stages, but it is not a required ingredient for a community. In the long run, continuous interactions among members enable them to build common identity; they also promote diversity. Over time, members develop their own styles and approaches. They define their status within the community by participating in discussions and developing interpersonal relationships. Exemplifying diversity in skills, ideas, and perspectives makes a CoP a richer creative learning environment for its members.

Mutual engagement of members is a personal matter and therefore a source of coherence for the community (Wenger, 1998). From this aspect, participation is voluntary, and it does not really matter how members join, or whether they are self-selected, or assigned to the community. As they participate in the community activities at various levels, they become the part of the community. Wenger (2001) identifies four levels of participation in a CoP as (1) core participants, (2) active participants, (3) peripheral participants, and (4) outsiders.

A small group of people who actively participate in activities of the community often lead and coordinate the community with topics and agendas they determine. The core group constitutes ten to fifteen percent of the whole community. The next level is the active group who attends and participates in the activities but not as regularly as the core group members do. The active group is also small and constitutes fifteen to twenty percent of whole community. The majority of the CoP members are peripheral and seldom participate in the activities. Some remain peripheral because they think their state of knowledge is not relevant to the rest of the community or carries no authority, or they do not have enough time to contribute. Outsiders are not the members of the community but they may have an interest in the community.

Petter et al. (2007) argue that Web 2.0, specifically social-networking software, can support and facilitate informal learning activities among members of a CoP. Further, they note that widespread availability of the Internet permits like-minded individuals to form virtual CoPs for knowledge sharing activities. Social-networking sites and Web 2.0 technologies drastically reduce the turnaround time necessary for $\mathrm{CoP}$ members to gain both explicit and tacit knowledge within a domain. The temporal and spatial limitations of previous forms of communication (e.g., conferences, newsletters/journals, static Web pages) are overcome by a constantly flowing conversation that blends the work and social lives of the CoP members. Members rely on this flowing conversation for professional development and meeting organizational goals.

Social-networking Sites

Boyd and Ellison (2007) define social-networking sites as "web-based services that allow individuals to (1) construct a public or semi-public profile within a bounded system, (2) articulate 
a list of other users with whom they share a connection, and (3) view and traverse their list of connections and those made by others within the system.” As the definition suggests, socialnetworking sites provide a venue for individuals to form networks, not only with their friends, colleagues, and co-workers, but also with strangers. However, such networks generally create weak ties among members, since most members are casual acquaintances and resources and information exchange may be rare (Haythornthwaite, 2005). Further, boyd and Ellison (2007) argue that a shared offline connection among some of the members, despite these weakly tied relationships, plays an important role in creating virtual social circles.

SixDegrees.com is recognized as the first social-networking site and was founded in 1997 (boyd \& Ellison, 2007). Since then, the basic functions of such venues have remained the same: to connect individuals based on common interests, friends, or objectives. Today's social-networking sites rely heavily on Web 2.0 technologies and applications to provide users with more interactive and content-rich environments, and to facilitate the communication processes among their members as seamlessly as possible. Social-networking sites have policies, procedures, rules, and reporting mechanisms to guide, govern, and control activities of their members and thus to provide a safe online social environment. Nadjm (2007) argued that “content moderation” tools such as filtering play a critical role in creating a safe social environment not only for individuals and privacy related issues, but also for organizations through protection of intellectual property.

Ellison et al. (2007) found that social-networking sites support preexisting interpersonal offline relations and help individuals keep in touch regardless of geographical and physical boundaries. The networks that are established in social-networking sites are generally formed around people as personal networks (boyd \& Ellison, 2007). Further, Carter's (2005) findings suggest that personal relationships initiated online can often move to an offline environment and become part of people's daily lives.

\section{Social Capital}

Social capital can be defined from the CoP perspective as "the common social resource that facilitates information exchange, knowledge sharing, and knowledge construction through continuous interaction, built on trust and maintained though shared understanding" (Daniel et al., 2003). It is often used as a model to explain various social issues in social groups such as city neighborhoods and is widely discussed in sociology and political science literature (Daniel et al., 2003; Lesser \& Storck, 2001). Lesser and Storck (2001) argue that social capital is a part of CoPs and gives rise to behavioral changes that, in turn, improves on organizational performance. Their study of communities existing within different organization (e.g., manufacturing, lending, pharmaceutical) suggests that CoPs reduce the learning curve for new employees by helping them identify knowledge resources within the company, facilitate rapid response to customer inquiries by connecting professionals and expertise, and reduce reinvention by improving reuse of existing knowledge assets. Moreover, they indicated that CoPs serve as generators of social capital by developing, promoting, and nurturing connections and relationships among practitioners regardless of their physical locations and official statuses. In turn, social capital provides a platform where a sense of trust and mutual obligation, shared common language, and context constitute the foundation.

Putnam (2000) notes the importance of mutual obligations and reciprocity in social networks and makes a distinction between bridging (inclusive) and bonding (exclusive) social capital. He defines bridging social capital as the loose connections or weak ties among individuals that allow them to access external resources, information and perspectives, and which facilitates the diffusion of information. Bonding social capital is defined as the links between closely connected individuals such as family members or close friends. Ellison et al.'s (2007) findings suggest an 
additional dimension called maintained social capital that explains the ability to stay connected as members of a community move through life. Further, they found that there is a strong association between use of a social-networking site and the three dimensions of social capital: bonding, bridging, and maintained.

\section{COLLABORATION IN PRACTICE}

The Internet, specifically Web 2.0, redefines, reshapes, and transforms the information and knowledge landscape and how we relate to information and media. Worldwide availability of the Internet and broadband access increases spontaneous encounters and, in turn, virtual CoPs can be easily formed and sustained. Wikipedia (www.wikipedia.org), the biggest multilingual freecontent encyclopaedia on the Internet, and SourceForge (www.sourceforge.net), the world's largest development and download repository of Open Source code and applications, serve as living products of such encounters and examples of collaborative projects conducted as a community. The popularity of Wikipedia has recently sparked a new Google project called Knol (knol.google.com), a platform for information sharing, that lets users produce knowledge products on any topical area and collaborate with other authors.

Second Life (SL) (www.secondlife.com), a 3D multi-user virtual environment, has served millions of users in a virtual community since its inception in 2003. As in other Web 2.0 applications, residents of SL are able to create their own social spaces and interact with each other. Companies such as IBM have their own SL existence that allow their employees, partners, clients, and other interested parties to meet, learn, engage in business activities, and collaborate with each other. Libraries, museums, and educational institutions from all over the world are also trying to leverage the functionalities offered in this online environment by building collaborative learning environments (Calongne \& Hiles, 2007; Marty \& Twidale, 2007; McLean, 2007). Organizations can create areas such as cafés and conference rooms to allow community members to get together, interact, and improve user engagement.

Oguz (2007) found that Web 2.0 applications, such as Wikis, instant messaging, and discussion boards, facilitate building and maintaining communities of practice in academic library digital project collaborations. Further, he noted that CoPs played an important role in enabling staff members to access up-to-date and experienced-based knowledge, provided a distributed problem solving and learning environment, facilitated informal communication and collaborative activities, and informed the decision-making process.

In early 2005, the authors Marsh and Oguz initiated a CoP in conjunction with their research center activities at the University of North Texas. Marsh, recognizing the synergies between regional radio-frequency identification (RFID) business and local university researchers, originated open forums to introduce potential collaborators. Interests ranged from retail and marketing to information systems, transportation services and security. Local RFID experts from manufacturing, retail, systems, engineering, and security joined the forums for presentation and open discussions, resulting in collaborations and projects. An original group of around ten grew to a network of over fifty participants and approximately eight sub-groups. During this process a virtual knowledge base is created for capturing conferences, presentations, and resources to create and promote an online community identity. This mix of personal and web-based contact provided faster communications and knowledge exchange leading to a high level of internet discoverability. 


\section{A Virtual Community of Practice: The Library Society of the World}

The Library Society of the World (LSW) (thelsw.org) is an informal community of librarians that formed to provide community and support outside of the confines of the American Library Association (ALA). As founding member Joshua M. Neff describes:

A bunch of us library types were chatting on Twitter one day, complaining about the ALA. My chief complaint was (and still is) that I can't actively participate in the ALA, because it costs too much (basic membership plus joining divisions or round tables plus attending in-person meetings) compared to what I get paid. Someone, I can't remember who, suggested that internet technologies should allow us to create our own grassroots library association. Someone else issued a dare to start something. Inspired, I came up with a name I liked (being a long-time fan of superhero comics like "Justice Society of America"), quickly created a logo and created a wiki. Then I sent out a link to the wiki on Twitter and let word of mouth spread from there (personal communication, August 24, 2008).

And word of mouth spread quickly: the loosely connected CoP of techie librarians (technology savvy) soon gathered around the principles of an informal and often humorous approach to collaboration. This informality displays a degree of trust found in social capital. Coleman (1990, p.304) argued that "social capital is created when the relations among person change in ways that facilitate action... a group whose members manifest trustworthiness and place extensive trust in one another will be able to accomplish much more than a comparable group lacking that trustworthiness and trust." Much of the language used to define both CoPs and social capital is echoed in the experience of Iris Jastram, another founder of LSW:

We saw a need for a grassroots community to work together to support each other professionally, provide point-of-need professional development for each other, and develop social ties together. We were able to fill that need because the original community gelled at a time when key social tools online were mature enough to make this kind of blended professional and social interaction effortless. And I'd like to emphasize (again) the blend of professional and social interaction that has always been a fundamental part of what we do. Take the social element out and we wouldn't have the trust level to lay bare our ignorance and ask "silly" questions. Take the professional element out and it would fall by the wayside as we got busy with our day-to-day jobs. The blend is key (personal communication, August 26, 2008).

This informality and the relaxed approach to community highlight much of what members were looking for. Members' comments suggest that as the LSW developed, weak ties between members became stronger as the bridging social capital increased. Members are able to actively engage in discussions and contribute to the LSW because of its foundation in Web 2.0 technologies. Without the initial conversations among techie librarians using Twitter (www.twitter.com), a micro-blogging tool, the idea for the community may have never happened. After the initial conversation, a wiki was created to capture and codify the conversation that was happening among members. This was followed by a Meebo room (www.meebo.com/rooms) where members could chat freely and later other social-networking sites and Web 2.0 technologies (e.g., interactive discussion forums using Tanger (www.tangler.com), Flicker (www.flickr.com) and LibraryThing (www.librarything.com) groups) to keep the members better connected and capture and disseminate knowledge generated in the community. With communication options being spread across several Web 2.0 technologies, the best applications became those that were used the most. As one member describes, "As an LSW branded thing, I'd say the Meebo room has been the most rewarding for me. Just by having the occasional 
conversation there with colleagues, I would say I have indirectly helped about 50 different libraries and thousands of library customers. In return, I would have received an equal 50 helps back" (personal communication, August 27, 2008). This serves as an example of the reciprocity found in the social capital as described by Putnam (2000) and reflects upon two important characteristics of CoPs, sense of belonging and mutual engagement, as Wenger et al. (2002) described.

Members of a CoP often recognize the difference between traditional bureaucratic organizations and informality in interactions in CoPs. As another member states:

[M]y initial understanding of LSW was that it would be an alternative to other professional organizations. But it's so different from every other professional organization I've been involved with that I think it's unfair to call it an alternative. To me, it's become a new way of communicating with and learning from my colleagues. It's less formal, yes, but I feel like I have richer interactions more frequently because of it” (personal communication, August 25, 2008).

However, despite its informal atmosphere and short age, the LSW has already served as a forum for professional collaboration. In addition to the creation of a collaboratively managed website and blog, core members of the CoP have given professional presentations on the LSW's formation and growth, and a free, online professional development conference is being planned.

Web 2.0 technologies are making it possible for these communities to reach a broader population, thereby increasing the social capital of their members. Where traditional professional organizations have been bound by geography, discipline, or the ability to pay dues, CoPs like the LSW are being born online, reaching out to members across the globe, and encouraging a discussion of social and domain-specific topics that benefit their members.

\section{The Community Pulse: friendfeed}

Not all CoPs are as formal as the LSW. Many of the techie librarians who are members of LSW also socialize with peripheral members and outsiders via Web 2.0 technologies. One socialnetworking site has played an important part in this broader $\mathrm{CoP}$ is friendfeed (friendfeed.com). friendfeed is a social aggregator-users can connect the accounts that they hold on various social websites (e.g., YouTube, MySpace, Facebook, del.icio.us, Twitter, LinkedIn, and Flickr). Once these accounts are linked, the user and his or her friends will see a stream of that user's activity from each of these separate accounts on friendfeed. Additionally, users can like a post (showing interest/approval), and they can also comment on each others' online activity, which allows for both professional and social interaction as shown in Figure 1. 


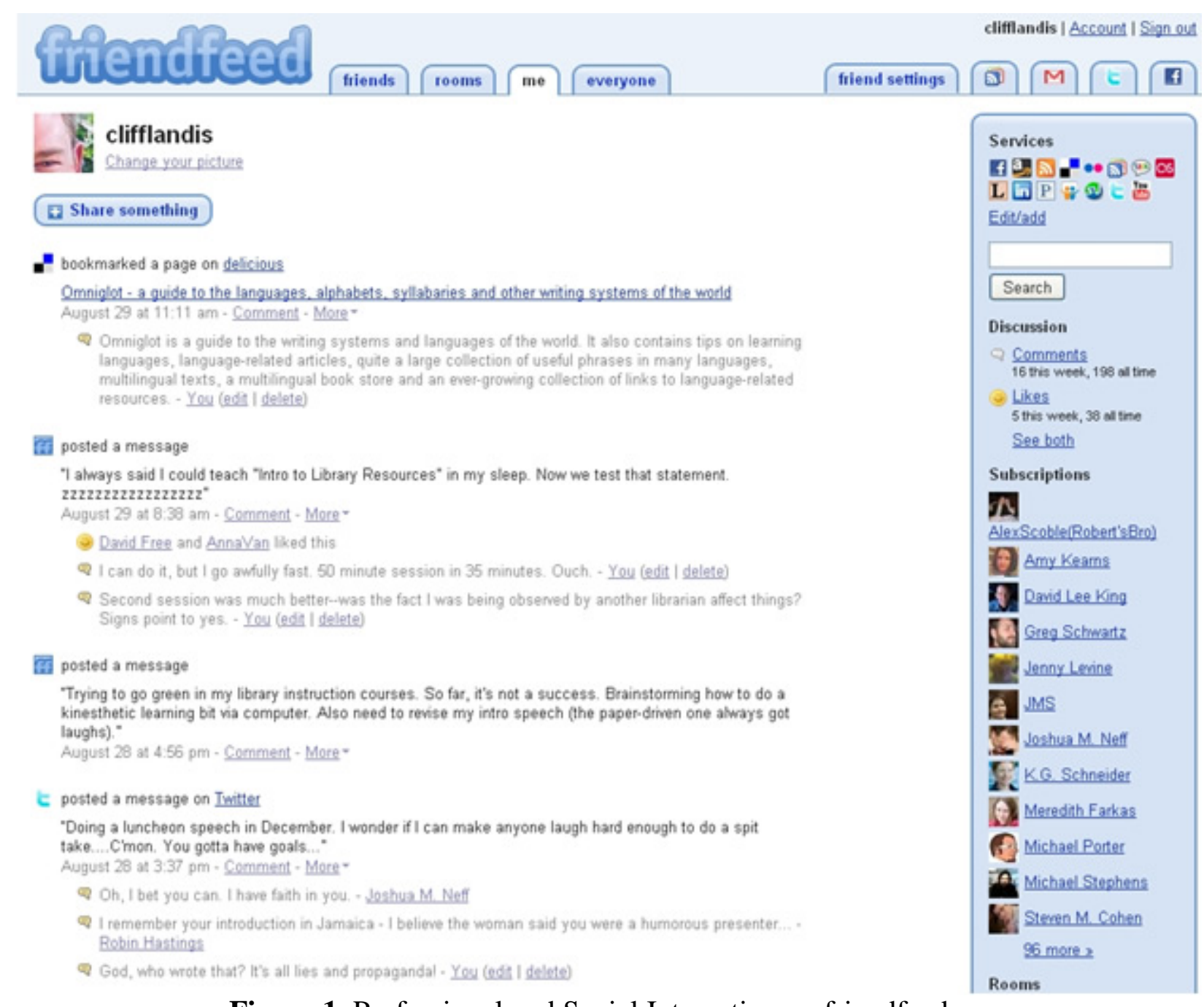

Figure 1. Professional and Social Interaction on friendfeed

The ability for CoP members to engage each other in conversation about their online activity can have a profound impact on the professional development and social capital. For example, a recent message reflects on the impact of social media: "Social software has brought about an entirely new aspect of the psyche: the extra-ego, or hyper-ego. I have outsourced part of my psyche to a self-selected peer group, which acts as a validator, gut-check, and willing audience for a selection of my accomplishments and foibles” (personal communication, August 25, 2008). This post not only illustrates the nature of a virtual CoP and the impact of social capital on its members, but it also demonstrates the role of a social-networking site as an information sharing platform.

As Web 2.0 applications such as friendfeed have emerged, collaborative behavior typically found in a CoP has been visibly altered. Traditional collaborative practices such as information seeking, discovery, dissemination and evaluation have been freed from the previous limitations of geography. CoP members can now seek the input of domain experts in real-time, regardless of their organizational affiliation or location on the globe. In addition, the turn-around time for domain communication and collaboration has been significantly reduced. This ongoing conversation contributes to members' professional growth and development. As one member states, "I love how much I learn on friendfeed, and how much I can bring back to my own library. I don't get out to conferences a lot, but I almost feel as if I did, because there's so much to learn from colleagues on the social web" (personal communication, August 25, 2008). This ability for virtual CoPs to overcome the barriers that slowed communication for face-to-face CoPs will have a strong impact on traditional organizations and their members in the future. 


\section{LEARNING AND KNOWLEDGE PROCESSING IN CoPs}

In order to examine the benefits and challenges of CoPs it is important to explore the process of knowledge creation, the nature of human knowledge, and the transfer of knowledge in the CoP domain.

Polanyi (1966) categorizes human knowledge as (1) explicit and (2) tacit knowledge. The distinction between tacit and explicit knowledge is based on the codability of the knowledge, or the ability to be put into words. Explicit knowledge is easy to specify, document, express verbally and in print, and access. It can be coded and transferred easily via formal channels from one location or organization to another (Persaud et al., 2001). Tacit knowledge, on the other hand, may not be easily accessible; it is intuitive and experience based. Tacit knowledge cannot be coded and easily transferred (Nahapiet \& Ghoshal, 1998); it makes data and fact more meaningful to others who lack that particular tacit knowledge (Persaud et al., 2001). Tacit knowledge is more actionable knowledge, therefore more valuable as opposed to explicit knowledge (Marwick, 2001).

Nonaka (1994) proposes that there are four modes of knowledge conversion: (1) from tacit knowledge to tacit knowledge (socialization), (2) from explicit knowledge to explicit knowledge (combination), (3) from tacit knowledge to explicit knowledge (externalization), and (4) from explicit knowledge to tacit knowledge (internalization). His model is based on the assumption that "knowledge is created through conversion between tacit and explicit knowledge" (p.18). Although tacit knowledge cannot be articulated or easily put into words, a shared repertoire developed in CoPs facilitates communication of tacit knowledge.

Gannon-Leary and Fontainha (2007) list several success factors, including the sense of belonging and trust, within virtual CoPs. They also delineate several challenges that serve as barriers to virtual CoPs such as cognitive and cultural barriers, legal issues (e.g., intellectual property), and lack of face-to-face interaction. In addition, anonymity, or hidden identities in an online environment, is cited as another potential barrier that prevents members from getting to know each other and build trust, both of which are critical to information sharing. Further, participation by a small number of members as opposed to larger number of sideliners, read-only participants, discourages participation. These read-only participants are not uncommon to traditional CoPs in which sixty to seventy percent of the members are peripheral whereas about fifteen to twenty percent of the members regularly participate in community activities and provide direction for the community (Wenger et al., 2002). It appears that participation-related issues frustrate those who contribute regularly and have a negative effect on coherence for the virtual community.

As Leadbeater (2008) argues, the vast openness of the Web, pervasive use and availability of interactive tools and social-networking on the Internet allows anyone to connect to anyone regardless of organizational or geographic boundaries and facilitate serendipitous encounters, which generates new possibilities for collaboration and helps improved cohesion among individuals.

\section{FUTURE RESEARCH AND DIRECTIONS}

Despite the pervasive impact that the Internet has had since its creation, social media is still a technology in its infancy. Therefore, we are only beginning to see the impact that social media will have on collaborative activities and virtual CoPs over time. Longitudinal studies of CoPs may help us better understand how these communities grow and change over time, especially considering that more and more, thanks to social media and Web 2.0 technologies, these communities are being born online. A further study on the maintained social capital introduced by Ellison et al. (2007) may reveal important insights about members' connections in virtual CoPs 
and its impact on organizational performance. As social-networking sites have gained in popularity, users have been able to reconnect with people from their past. But what will be the impact of relationships that are started and maintained online, throughout the lifespan of CoP members?

\section{CONCLUSION}

We now have the ability to create and maintain relationships completely online; relationships that can span the entire distance of the globe with little inconvenience. The advent of Web 2.0 technologies and social media have made it possible for CoPs to establish a new environment for collaboration completely online. This new online environment allows CoPs to reach more new members, regardless of their geographical location, experience level, or ability to financially contribute. It also allows CoP members to communicate and collaborate in less time, and with a broader range. These virtual CoPs allow members to create relationships and develop connections that would have been impossible to establish in the past. These relationships enable the transmission of tacit knowledge between CoP members, bringing context and meaning to the data, facts and numbers that members encounter each day. Each of these abilities has strong implications for both individuals and organizations.

Virtual CoPs' ability to nurture, foster, and transform tacit knowledge provides an unparalleled experience for their members. This ability also makes them an important part of the information environment in today's organizations, as those organizations make the transition to the digital age. CoPs provide their members with a rich and creative learning environment where they are able to gain considerably from diverse skills, ideas, and perspectives available in the community. Engaging in collaborative activities and knowledge sharing are essential to meet organizational goals.

At this point, many members of these virtual CoPs are early technology adopters, and are a minority of the overall population (Horrigan, 2007). However, as these technologies become more mainstream, ever more potential members of these CoPs will come online. Even now, we are seeing a strong impact from CoPs that are born digital. It is these CoPs that will serve as both formal and informal communication gateways for collaboration in the years to come.

\section{REFERENCES}

Bejune, M. M. (2007). Wikis in Libraries. Information Technology and Libraries, 26(3), 26-35.

Borgatti, S. (2004). Communities of Practice. Retrieved October 11, 2005, from http://www.analytictech.com/mb119/communities_of_practice.htm

Boyd, d. m., \& Ellison, N. B. (2007). Social network sites: Definition, history, and scholarship. Journal of Computer-Mediated Communication, 13(1). Retrieved August 20, 2007, from http://jcmc.indiana.edu/vol13/issue1/boyd.ellison.html

Calongne, C., \& Hiles, J. (2007). Blended Realities: A Virtual Tour of Education in Second Life. Paper presented at the 12th Annual TCC Worldwide Online Conference.

Carter, D. (2005). Living in Virtual Communities: An ethnography of human relationships in cyberspace. Information, Communication \& Society, 8(2), 148-167.

Cross, R., Parker, A., Prusak, L., \& Borgatti, S. P. (2001). Knowing What We Know: Supporting Knowledge Creation and Sharing in Social Networks. Organizational Dynamics, 30(2), 100-120. 
Coleman, J. S. (1990). Foundations of Social Theory. Cambridge: Belknap Press.

Daniel, B., Schwier, R. A., \& McCalla, G. (2003). Social Capital in Virtual Learning Communities and Distributed Communities of Practice. Canadian Journal of Learning and Technology, 29(3).

Ellison, N. B., Steinfield, C., \& Lampe, C. (2007). The Benefits of Facebook "Friends": Social capital and College Students' Use of Online Social Network Sites. Journal of ComputerMediated Communication, 12(4). Retrieved August 20, 2008, from http://jcmc.indiana.edu/vol12/issue4/ellison.html

Gannon-Leary, P. M., \& Fontainha, E. (2007). Communities of Practice and virtual learning communities: benefits, barriers and success factors. eLearning Papers. Retrieved September 1, 2008, from http://www.elearningpapers.eu/index.php?page=doc\&vol=5\&doc_id=10219\&doclng=6

Haythornthwaite, C. (2005). Social Networks and Internet Connectivity Effects. Information, Communication, and Society, 8(2), 125-147.

Hildreth, P., \& Kimble, C. (2004). Knowledge Networks: Innovation through Communities of Practice. London: Idea Group Publishing.

Horrigan, J. B. (2007, May 7). A typology of information and communication technology users. Retrieved from Pew Internet \& American Life Project: http://www.pewinternet.org/pdfs/PIP_ICT_Typology.pdf

Lave, J., \& E., W. (1991). Situated Learning: Legitimate Peripheral Participation. Cambridge: Cambridge University Press.

Leadbeater, C. (2008). We-think: The Power of Mass Creativity. London: Profile Books Ltd.

Lesser, E. L., \& Storck, J. (2001). Communities of practice and organizational performance. IBM Systems Journal, 40(4), 831-931.

Marty, P., \& Twidale, M. (2007). A Second Life for your Museum: 3D Multi-User Virtual Environments. Retrieved June 30, 2008, from http://www.archimuse.com/mw2007/papers/urban/urban.html

Marwick, A. D. (2001). Knowledge management technology. IBM Systems Journal, 40(4), 814830.

McLean, M. (2007). Library 2.0 and Libraries Building Community Initiatives in Australia. Retrieved June 30, 2008, from http://dlist.sir.arizona.edu/2270

Nahapiet, J., \& Ghoshal, S. (1998). Social capital, intellectual capital, and the organizational advantage. The Academy of Management Review, 23(2), 242-266.

Nadjm, M. (2007). Security Recommendations for Social Network Communities. Paper presented at the European e-Identity Conference. 
Nonaka, I. (1994). A Dynamic Theory of Organizational Knowledge Creation. Organization Science, 23(2), 14-37.

Oguz, F. (2007). An Exploration of the Diffusion of a New Technology from Communities of Practice Perspective: Web Services Technologies in Digital Libraries. Unpublished Dissertation, University of North Texas, Denton, Texas.

Persaud, A., Kumar, U., \& Kumar, V. (2001). Harnessing Scientific And Technological Knowledge For The Rapid Deployment Of Global Innovations. Engineering Management Journal, 13(1), 12-18.

Petter, C., Reich, K., \& Helling, K. (2007). Social Software and the Establishment of Virtual Communities of Practice in the Tourism Sector. eLearning Papers. Retrieved September 1, 2008, from

http://www.elearningpapers.eu/index.php?page=volume_pdf_download\&vol=5

Polanyi, M. (1966). The Tacit Dimension. New York: Anchor Day Books.

Putnam, R. D. (2000). Bowling Alone: The Collapse and Revival of American Community. New York: Simon \& Schuster.

Wenger, E. (1998). Communities of Practice: Learning, Meaning, and Identity. Cambridge: Cambridge University Press.

Wenger, E. (2001). Supporting communities of practice: a survey of community-oriented technologies. Retrieved September 1, 2008, from http://www.ewenger.com/tech/index.htm

Wenger, E. (2004). Knowledge Management as a doughnut: Shaping your knowledge strategy through communities of practice. Ivey Business Journal. Retrieved August 20, 2008, from http://www.iveybusinessjournal.com/view_article.asp?intArticle_ID=465

Wenger, E., McDermott, R., \& Snyder, W. M. (2002). A Guide to Managing Knowledge: Cultivating Communities of Practice. Boston: Harvard Business School Press. 